\title{
Differences in interrenal tissue, biosynthetic capacity and ACTH sensitivity in progeny of sea bream from parents selected for high or low cortisol response
}

\author{
J. Rotllant*††, D. Monteroß, M. J. Caballero \\ L. Robaina $\S$, M. S. Izquierdo $\S$ And L. Tort $\dagger$ \\ *Centre of Marine Science, CCMAR, University of Algarve, Campus de Gambelas, \\ 800-810 Faro, Portugal †Department of Cell Biology, Physiology and Immunology, \\ Universitat Autonoma de Barcelona, 08193-Bellaterra, Spain and §Grupo de \\ Investigación en Acuicultura, Instituto Canario Ciencias Marinas, \\ Telde, Gran Canaria, Spain \\ (Received 8 August 2001, Accepted 16 December 2002)

\begin{abstract}
Progeny of sea bream Sparus aurata from parents selected for high or low cortisol response to stress also showed similar divergent cortisol response after $48 \mathrm{~h}$ of handling and confinement stress. The high response progeny, however, had a lower basal unstimulated cortisol release and ACTH-stimulated cortisol output in vitro.

(C) 2003 The Fisheries Society of the British Isles
\end{abstract}

Key words: ACTH; cortisol; head kidney; sea bream; stress.

Selection for high and low cortisol response in fishes has been undertaken in salmonid and cyprinid species (Fevolden et al., 1991; Tanck et al., 2002). Recently, selection for divergent cortisol response after repeated stress has also been carried out in sea bream Sparus aurata L. (Tort et al., 2001). As demonstrated by Pottinger \& Carrick (2001), however, it is not clear which level of the endocrine axis is responsible for the phenotypic characters used for this differential selection. This study examined whether the observed plasma cortisol differences in sea bream selected for their cortisol response to stress arose from differences in interrenal function. The present work studied the interrenal biosynthetic capacity and the sensitivity to ACTH in first generation sea bream from parents that showed a high or low response to handling and confinement stress (Tort et al., 2001).

Sea bream weighing $(878 \pm 127 \mathrm{~g})$ were obtained from the facilities of the Instituto Canario de Ciencias Marinas (Las Palmas, Canary Islands, Spain). These fish were a first generation progeny obtained from breeders that showed either high or low cortisol levels after repeated handling and confinement stress

$\$$ Author to whom correspondence should be addressed. Tel.: +351289800900 ; fax: +351289818353 ; email: rotllant@ualg.pt 
(Tort et al., 2001). The experiment used two groups of progeny, from high or low responding parents each in four replicate tanks containing eight fish per tank (density, $7 \mathrm{~kg} \mathrm{~m}^{-3}$ ). Two tanks from each progeny group (16 fish) were sampled as controls and the remaining tanks were subjected to handling and confinement stress (netted and transferred to small net cages at a density of $200 \mathrm{~kg} \mathrm{~m}^{-3}$ ) for $48 \mathrm{~h}$ and sampled thereafter. At sampling, all fish belonging to the same sampling group were quickly anaesthetized in 2-phenoxyethanol (1: $1000 \mathrm{v} / \mathrm{v}$; Sigma, St Louis, MO, U.S.A.) and blood was collected from the caudal vessels with a $2 \mathrm{ml}$ syringe containing EDTA $\left(1.5 \mathrm{mg} \mathrm{ml}^{-1}\right.$ blood). Plasma aliquots were separated and frozen $\left(-20^{\circ} \mathrm{C}\right)$ until analysis was performed. Head kidneys were quickly dissected after sampling ( $n=8$ per group and treatment). The tissues were placed in superfusion chambers and superfused with a buffered HEPES Ringer solution (HEPES $15 \mathrm{mM}$; pH 7.38) containing $\mathrm{NaCl}(171 \mathrm{mM}), \mathrm{KCl}(2 \mathrm{mM}), \mathrm{CaCl}_{2} \cdot 2 \mathrm{H}_{2} \mathrm{O}(2 \mathrm{mM}), 0 \cdot 25 \%(\mathrm{w} / \mathrm{v})$ glucose and $0.03 \%(\mathrm{w} / \mathrm{v})$ bovine serum albumin. This medium was pumped through the superfusion chambers at a rate of $75 \mu \mathrm{min}^{-1}$ by means of a multichannel peristaltic pump (Gilson). Previous results indicated that cortisol reaches stable baseline levels after $3 \mathrm{~h}$ of superfusion (Rotllant et al., 2000a, b). Therefore, after $3 \mathrm{~h}$, tissue was stimulated at a concentration of $5 \mathrm{nM} \mathrm{hACTH}{ }_{1-39}($ Sigma $)$ during $20 \mathrm{~min}$. For each fish the maximum cortisol release due to ACTH stimulation was compared with the baseline release in order to obtain the stimulation factor of ACTH, defined as (maximum release - baseline release)

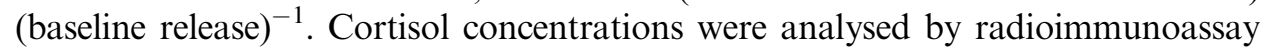
following the procedure described in Rotllant et al. (2000a).

Results are given as mean \pm S.E. One-way ANOVA was applied followed by the Student-Newman-Keuls (SNK) test to check differences between particular groups. The level for accepted statistical significance was $P<0 \cdot 05$.

The levels of plasma cortisol in progeny of high (HR) and low (LR) responding sea bream under control conditions and after $48 \mathrm{~h}$ handling and confinement stress are shown in Fig. 1. High response progeny had significantly higher plasma cortisol levels before and after $48 \mathrm{~h}$ handling and confinement stress. The kinetics of cortisol in vitro release from the head kidneys of HR and LR progeny, before and after handling and confinement stress, are shown in Fig. 2. These results are summarized in Fig. 3. No differences were found in the initial unstimulated cortisol release of stress and non-stress fish from both progeny groups $(P>0 \cdot 05)$. Basal unstimulated cortisol release (Fig. 3) was significantly higher in control HR progeny $(P<0.05)$ than in LR progeny. An increase of the basal unstimulated cortisol release in LR progeny $(P<0 \cdot 01)$, however, was found after $48 \mathrm{~h}$ stress. The stressor did not affect the basal cortisol release of HR progeny.

The results of this study show that the progeny of HR sea bream have higher pre- and post-stress cortisol levels. The progeny of LR fish had cortisol levels similar to previously published values for sea bream (Rotllant et al., 2000b, 2001). It appears that the LR progeny were more sensitive to the $48 \mathrm{~h}$ handling and confinement stress: the HR progeny showed a 3.5-fold increase while the LR progeny showed a 9.7-fold increase in plasma cortisol levels. The results obtained in the levels of basal unstimulated and stimulated cortisol release from the in vitro superfusion clearly indicate a different response of the interrenal tissue depending on the group selected. Therefore, a different sensitivity to 


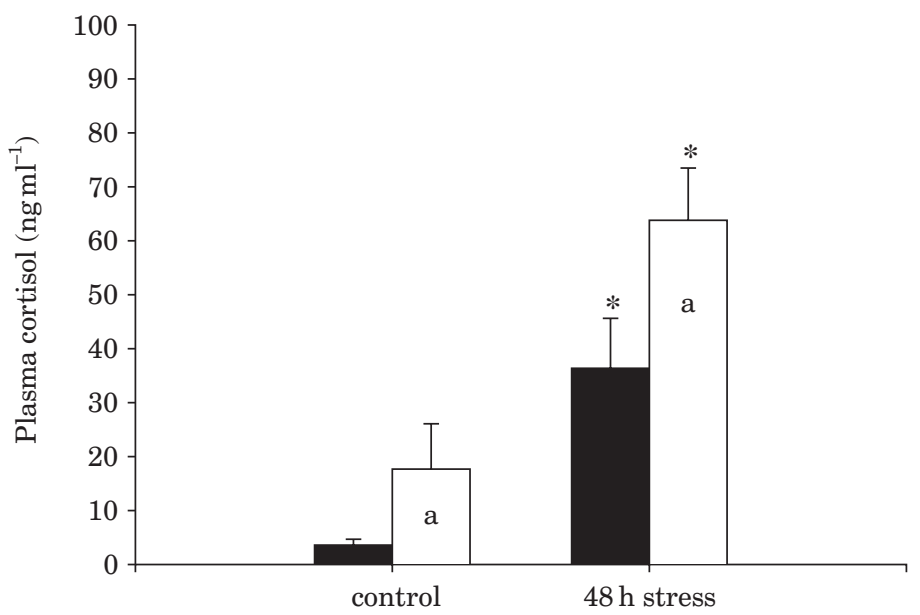

Fig. 1. Changes in mean \pm S.E. $(n=16)$ plasma cortisol levels in low response (LR, $\mathbf{\square})$ and high response (HR, $\square$ ) progeny of sea bream subjected to $48 \mathrm{~h}$ handling and confinement stress. Differences between treatments and controls $\left(^{*}, P<0.01\right)$ and between progeny $(\mathrm{a}, P<0.05)$ are indicated.

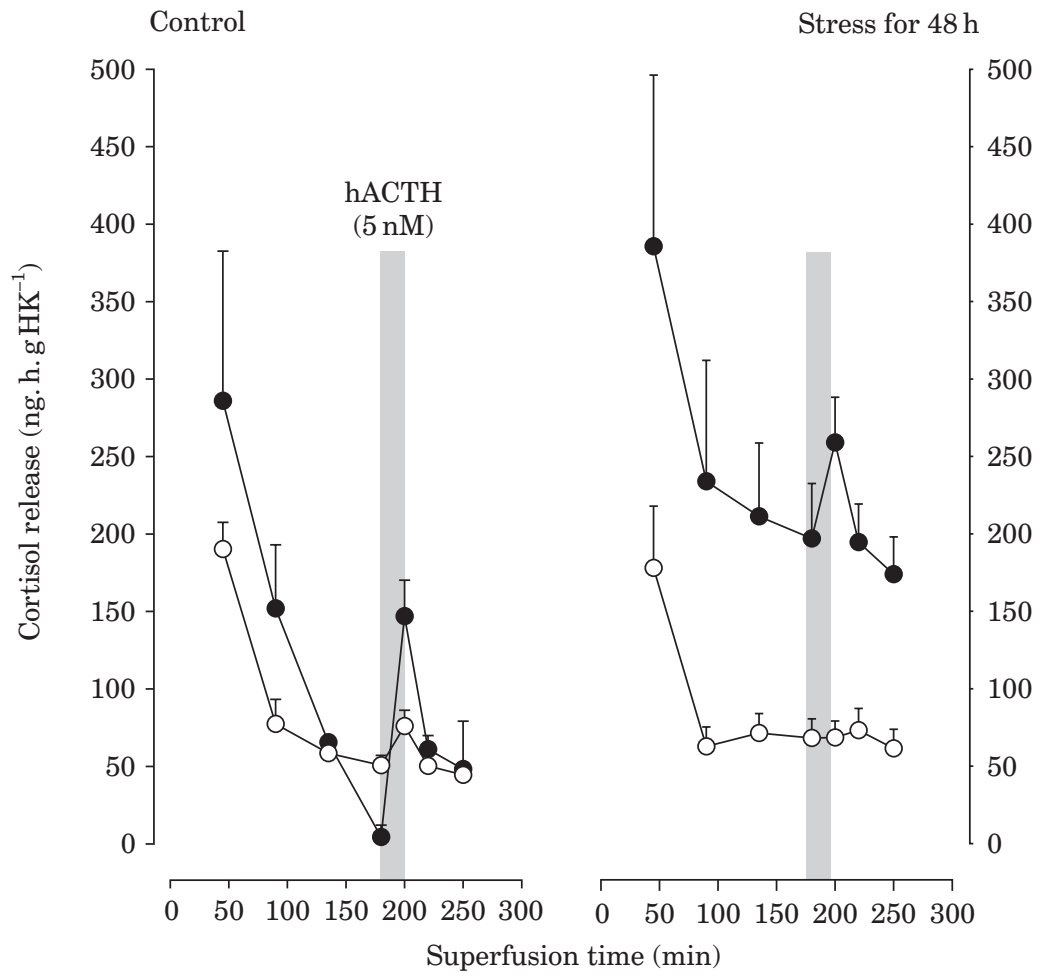

Fig. 2. Comparison of the effects of $48 \mathrm{~h}$ handling and confinement stress on in vitro head kidney cortisol release (mean \pm s.E., $n=8$ ) after a pulse of $5 \mathrm{nM} \mathrm{hACTH}_{1-39}$ for $20 \mathrm{~min}$ in progeny of low $(\boldsymbol{\square})$ and high $(\square)$ responding sea bream. Vertical bars correspond to the $20 \mathrm{~min}$ period of stimulation with ACTH. 


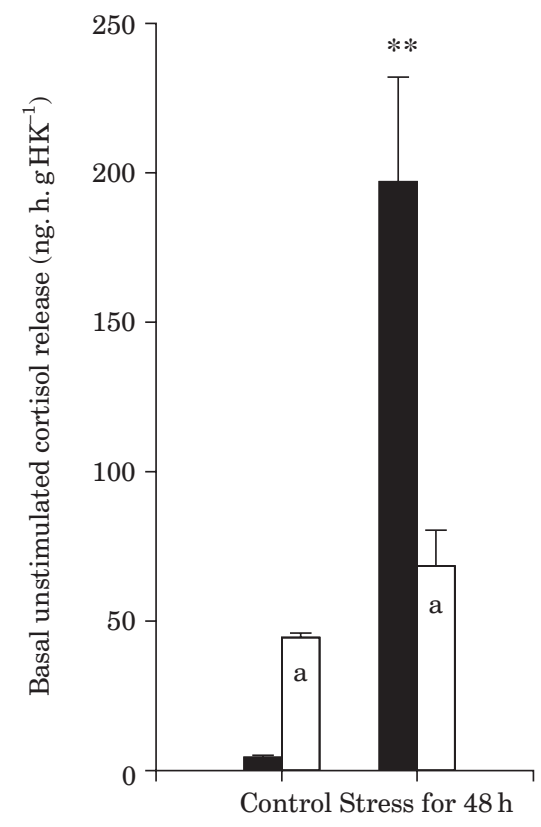

FIg. 3. Analysis of the effects of $48 \mathrm{~h}$ handling and confinement on in vitro cortisol basal release, measured in the fraction collected at $180 \mathrm{~min}$ in low response $(\boldsymbol{\square})$ and high response $(\square)$ progeny of sea bream. Values are mean \pm S.E., $n=8$. Differences between treatments and controls $(* *, P<0.001)$ and between progeny $($ a, $P<0.05)$ are indicated.

ACTH and also a different biosynthetic capacity of the interrenal tissue is suggested. The response of LR progeny fish was similar to previously published data for sea bream (Rotllant et al., 2000a, b), i.e. a low corticosteroid biosynthesis by the interrenal under control conditions and a high sensitivity when stimulated with $5 \mathrm{nM}$ ACTH. Progeny of HR fish showed the opposite, i.e. the unstimulated tissue had a higher basal cortisol release, and after ACTH stimulation at the same concentration the response detected was not significantly different between control and stressed fish. The combination of effects observed in the non-stressed progeny of HR fish (elevated plasma cortisol levels and enhanced secretory activity of the unstimulated interrenal cells) appears to be similar to the effects observed after 23 days of crowding (Rotllant et al., $2000 b$ ). So, this type of dynamic response possibly represents a characteristic response of long-term chronically stressed fish (Montero et al., 1999; Rotllant et al., 2000b). The progeny of HR fish had the highest cortisol levels in plasma after $48 \mathrm{~h}$ of handling and confinement stress, yet were unresponsive to ACTH and cortisol production in vitro was low. These results are in agreement with the recent results obtained in rainbow trout Oncorhynchus mykiss (Walbaum) by Pottinger \& Carrick (2001). These authors conclude that the divergence of stress responsiveness between $\mathrm{HR}$ and $\mathrm{LR}$ rainbow trout arises from interrenal factors such as ACTH receptor density, steroidogenic capacity, interrenal tissue mass or post-interrenal factors such as the rate of cortisol metabolism and clearance. Pottinger \& Carrick (2001) state that the interrenal sensitivity to ACTH may be an important factor for HR, as it is in mammals (Gómez et al., 1996) and birds 
(Carsia et al., 1988). In these groups the difference of the corticosteroid response between strains was attributed to adrenal sensitivity to ACTH and therefore the adrenal volume was a main factor. From the results of the present work it is concluded that the differences observed in the concentrations of plasma cortisol levels between both sea bream progeny lines could be attributed, in part, to the biosynthetic capacity but not to the interrenal sensitivity to ACTH. Thus, other factors such as the density of ACTH receptors and the rate of clearance or metabolism of cortisol should be involved in the differences of the plasma cortisol stress response observed for progeny of high and low cortisol responding sea bream.

This work was supported by the RTD programme FAIR, CT95-152 of the Commission of European Communities. J. Rotllant was in receipt of a grant from Fundação de Ciência e Tecnologia (SFRH/BPD/1524/2000).

\section{References}

Carsia, R. V., Weber, H. \& Satterlee, D. G. (1988). Steroidogenic properties of isolated adrenocortical cells from Japanese quail selected for high serum corticosterone response to immobilisation. Domestic Animal Endocrinology 5, 231-240.

Fevolden, S. E., Refstie, T. \& Röed, K. H. (1991). Selection for high and low cortisol stress response in Atlantic salmon Salmo salar and rainbow trout Oncorhynchus mykiss. Aquaculture 95, 53-65.

Gómez, F., Lahamame, A., de Kloet, E. R. \& Armario, A. (1996). Hypothalamicpituitary-adrenal response to chronic stress in five inbred rats strains: differential responses are mainly located at the adrenocortical level. Neuroendocrinology 63, 327-337.

Montero, D., Izquierdo, M. S., Tort, L., Robaina, L. \& Vergara, J. M. (1999). High stocking density produces crowding stress altering some physiological and biochemical parameters in gilthead seabream Sparus aurata juveniles. Fish Physiology and Biochemistry 20, 53-60.

Pottinger, T. G. \& Carrick, T. R. (2001). ACTH does not mediate divergent stress responsiveness in rainbow trout. Comparative Biochemistry and Physiology A 129, 399-404.

Rotllant, J., Balm, P. H. M., Pérez-Sánchez, J., Weendelar-Bonga, S. E. \& Tort, L. $(2000 a)$. A decrease in ambient temperature results in a transient reduction of interrenal ACTH responsiveness in gilthead sea bream (Sparus aurata, L.). Fish Physiology and Biochemistry 23, 265-273.

Rotllant, J., Balm, P. H. M., Ruane, N. M., Pérez-Sánchez, J., Wendelaar Bonga, S. \& Tort, L. (2000b). Pituitary proopiomelanocortin-derived peptides and hypothalamicpituitary-interrenal axis activity in gilthead sea bream (Sparus aurata) during prolonged crowding stress: differential regulation of adrenocorticotropin hormone and melanocyte-stimulating hormone release by corticotropin-releasing hormone and thyrotropin-releasing hormone. General and Comparative Endocrinology 119, $152-163$.

Rotllant, J., Balm, P. H. M., Pérez-Sánchez, J., Wendelaar Bonga, S. E. \& Tort, L. (2001). Pituitary and interrenal function in gilthead sea bream (Sparus aurata) after handling and confinement stress. General and Comparative Endocrinology 121, 333-342.

Tanck, M. W. T., Claes, T., Bovenhuis, H. \& Komen, J. (2002). Exploring the genetic background of stress isogenic progenies of common carp selected for high or low stress-related cortisol response. Aquaculture 204, 419-434.

Tort, L., Montero, D., Robaina, L., Fernández-Palacios, H. \& Izquierdo, M. S. (2001). Consistency of stress response to repeated handling in the gilthead sea bream, Sparus aurata. Aquaculture Research 32, 593-598. 